\title{
FORMACIÓN DE ESPELEOTEMAS EN EL NORESTE PENINSULAR Y SU RELACIÓN CON LAS CONDICIONES CLIMÁTICAS DURANTE LOS ÚLTIMOS CICLOS GLACIARES
}

\author{
A. MORENO ${ }^{*}$, A. BELMONTE ${ }^{2}$, M. BARTOLOMÉ 1,2 , \\ C. SANCHO ${ }^{2}$, B. OLIVA', H. STOLL ${ }^{3}$, \\ L.R. EDWARDS ${ }^{4}$, H. CHENG ${ }^{4}$, J. HELLSTROM 5 \\ ${ }^{1}$ Instituto Pirenaico de Ecología, CSIC, Campus Aula Dei, Av. Montañana 1005, 50059 Zaragoza. \\ ${ }^{2}$ Dpto. de Ciencias de la Tierra, Universidad de Zaragoza, C/ Pedro Cerbuna 12, 50059 Zaragoza. \\ ${ }^{3}$ Facultad de Geología, Universidad de Oviedo, C/ Jesús Arias de Velasco s/n, 33005, Oviedo. \\ ${ }^{4}$ Department of Geology and Geophysics, University of Minnesota, Minneapolis, MN 55455, USA. \\ ${ }^{5}$ Department of Earth Sciences, University of Melbourne, Parkville 3010 VIC, Australia.
}

RESUMEN. El crecimiento de espeleotemas está estrechamente ligado a climas templados caracterizados por un balance hidrológico positivo. Las temperaturas cálidas y la disponibilidad hídrica son condiciones que estimulan la producción de $\mathrm{CO}_{2}$ en el suelo por la vegetación y por los microrganismos y facilitan, por tanto, que aguas sobresaturadas en carbonato se infiltren en el sistema kárstico. Este trabajo recopila 158 dataciones de un total de 34 espeleotemas obtenidas en nueve cuevas distintas del noreste peninsular y permite distinguir para los últimos $400 \mathrm{ka}$ los periodos con crecimiento de espeleotemas. La relación de la formación de espeleotemas con los periodos interglaciares aparece clara, pero además se observa una influencia de los ciclos precesionales, siendo los periodos de máxima insolación aquellos más idóneos para el desarrollo de estas formaciones kársticas. Aunque el Holoceno es, sin duda, el periodo mejor representado con los registros disponibles, los últimos siglos no se caracterizaron por un gran desarrollo espeleotémico en las cuevas estudiadas.

Speleothem formation in Northeastern Iberian Peninsula under the influence of different climatic conditions over last glacial cycles

ABSTRACT. Speleothem growing is closely linked to warm climates with a positive hydrological balance. Mild temperatures and hydrological availability are conditions that tend to stimulate soil $\mathrm{CO}_{2}$ production due to denser vegetation cover and higher microbial activity. In such situations, waters enriched with dissolved carbonate are common and can infiltrate in the karstic system. This study compiles 158 dates from 34 speleothems collected in nine caves in the Northeastern Iberia to distinguish the time intervals with speleothem formation. A clear connection of speleothem growth and interglacial periods is established but 
precesssional influence is also observed, being periods of maxima insolation those with ideal conditions to produce karstic formations such as speleothems. The Holocene is without doubt the best represented period in the available records. However, last centuries were not characterized by an important development of speleothems in the studied caves.

Palabras clave: espeleotemas, interglaciares, Holoceno, sistemas kársticos. Key words: speleothems, interglacial, Holocene, karstic systems.

Enviado el 3 de noviembre de 2012 Aceptado el 29 de diciembre de 2012

*Correspondencia: Instituto Pirenaico de Ecología, CSIC, Campus Aula Dei, Av. Montañana 1005, 50059 Zaragoza. E-mail: amoreno@ipe.csic.es

\section{Introducción}

Las formaciones de espeleotemas (estalactitas y estalagmitas) son carbonatos secundarios que se forman en ambientes endokársticos de prácticamente todo el mundo. Estas formaciones constituyen un archivo excepcional de los cambios climáticos del pasado (tanto térmicos como hidrológicos) gracias a que las diferencias registradas en la concentración de elementos traza y en la composición isotópica de la calcita que constituye estos materiales suministran información sobre las condiciones climáticas en el momento de su formación (White, 2004). Así, el $\delta^{18} \mathrm{O}$ del carbonato precipitado está principalmente ligado a los valores isotópicos del $\mathrm{O}$ del agua meteórica (que a su vez está influido por la temperatura, la cantidad de precipitación, etc.) mientras que el $\delta^{13} \mathrm{C}$ está relacionado con los valores isotópicos del $\mathrm{CO}_{2}$ del suelo, que dependen del tipo de roca caliza sobre la que se desarrolla el sistema kárstico, de la vegetación y, en última instancia, del clima. Además de los isótopos y los elementos traza, otros parámetros como la tasa de crecimiento o el tipo de laminaciones anuales, se analizan habitualmente en los estudios paleoclimáticos de espeleotemas. Una de las mayores ventajas de este tipo de "paleoarchivos" frente a otros más comunes como los registros sedimentarios marinos o lacustres es su datación mediante la técnica del U-Th, que requiere tan solo 100-200 mg de calcita (Dorale et al., 2004) para asignar una edad muy precisa dentro de un amplio intervalo temporal (0-500 000 años). El desarrollo reciente de las técnicas de espectroscopía de masas de ionización térmica (TIMS) y posteriormente el uso de multicolectores (ICPMS-MC), que posibilitan realizar medidas de $\mathrm{U}$ y de Th muy precisas y con muy poca cantidad de muestra, ha supuesto un gran avance en las dataciones de espeleotemas.

La formación de espeleotemas se ha asociado frecuentemente a la existencia de un clima favorable, caracterizado por condiciones templadas o cálidas y por suficiente disponibilidad hídrica. Por eso, los hiatos en la precipitación del carbonato, tanto a nivel de una estalagmita, como a escala de toda una cueva, se relacionan con la entrada en periodos fríos (ej. Moreno et al., 2010) o con fases especialmente secas (Wang et al., 2008). Por lo tanto, el estudio en varias cuevas de las fases en las que hay crecimiento de espeleotemas 
frente a los periodos en los que no precipita carbonato puede ser un indicador válido de las condiciones climáticas del pasado. Además, para determinados periodos del pasado, la información de la variabilidad climática es muy escasa o poco ajustada por modelos de edad. Por ejemplo, en la Península Ibérica, la escasez de archivos paleoclimáticos terrestres que cubran más allá del último ciclo glaciar aporta un interés especial a este tipo de registros como fuentes potenciales de información de periodos secos o fríos del pasado.

En este trabajo recopilamos la información cronológica de 34 estalagmitas de un total de nueve cuevas localizadas en un transecto altitudinal (Pirineo-Prepirineo-Sistema Ibérico) y latitudinal (de $\mathrm{N}$ a $\mathrm{S}$ en el Noreste Peninsular). El periodo de tiempo comprendido en este estudio abarca los últimos tres ciclos glaciares (ca. 400 ka hasta la actualidad) pero la precisión de las dataciones nos permite centrarnos en la reconstrucción de los últimos $250 \mathrm{ka}$. Los resultados obtenidos se han comparado con otros registros paleoclimáticos de la Península Ibérica (ej. temperaturas marinas superficiales del margen ibérico (Martrat et al., 2007) o de carácter global (ej. curva SPECMAP y reconstrucción de la insolación).

\section{Material y métodos}

Un total de 34 espeleotemas se recogieron de nueve cuevas del Noreste peninsular organizadas en un transecto latitudinal de los Pirineos, Pre-Pirineos y Sistema Ibérico (Tabla 1, Figs. 1 y 2). Así, tres de las cuevas se encuentran en el Pirineo Central, en la provincia de Huesca: Espluca Alta de Lasgüériz o 5 de Agosto y Pot au Feu, en el Macizo de Cotiella, y Cueva de Seso en las cercanías de Boltaña. La Sima de Esteban Felipe está localizada en el Prepirineo, en Sierra de Guara (Huesca) mientras que las restantes cinco cuevas se encuentran en el Sistema Ibérico: dos en la provincia de Teruel (las Grutas de Cristal en Molinos, cueva abierta al turismo, y Recuenco en Ejulve), dos en la provincia de Soria (La Galiana Alta y la Sima del Carlista) y una en la provincia de Burgos (Fuentemolinos) (Tabla 1, Fig. 1). En todas las cuevas se seleccionaron muestras de estalagmitas en base a dos premisas: (1) no deteriorar la cueva, priorizando aquellas estalagmitas rotas o caídas y (2) obtener muestras de todas las diferentes generaciones de espeleotemas que a priori se identificaron en las cuevas mediante una aproximación geomorfológica. Las estalagmitas se cortaron longitudinalmente y submuestrearon (100-400 mg de calcita) para dataciones por las series de desintegración del Uranio.

El método de datación basado en la desintegración del Uranio se sustenta en la existencia de dos isótopos padres naturales $\left({ }^{238} \mathrm{U}\right.$ y $\left.{ }^{235} \mathrm{U}\right)$, relativamente abundantes en la corteza, cuya evolución radiactiva final genera isótopos estables como el ${ }^{206} \mathrm{~Pb}$ y ${ }^{207} \mathrm{~Pb}$, aunque existen hijos intermedios tales como ${ }^{234} \mathrm{U},{ }^{230} \mathrm{Th},{ }^{226} \mathrm{Ra}$ y ${ }^{231} \mathrm{~Pa}$. Gracias a que el $\mathrm{U}$ es un elemento muy móvil y soluble, se incorpora rápidamente al ciclo hidrológico y puede ser transportado por aguas bicarbonatadas. Si a partir de estas aguas con Uranio en los carbonatos disueltos se forma un espeleotema éste contendrá una cantidad de U que se irá desintegrando y se transformará en ${ }^{234} \mathrm{~Pa}$ y ${ }^{230} \mathrm{Th}$, los cuales son insolubles y, por tanto, menos frecuentes en las aguas continentales. Para las dataciones en espeleotemas se utilizan el ${ }^{234} \mathrm{U}$ y ${ }^{230} \mathrm{Th}$ (isótopos intermedios) que proceden de la descomposición del ${ }^{238} \mathrm{U}$. Las dataciones darán edades reales siempre y cuando se cumplan estos tres requisitos; (1) que el 
Tabla1. Listado de cuevas exploradas y de estalagmitas analizadas por la técnica del U-Th. Datos climáticos obtenidos del Atlas Climático Digital de la Península Ibérica (Ninyerola et al., 2005), salvo que se indique otra fuente.

\begin{tabular}{|c|c|c|c|c|c|c|c|}
\hline & Cueva & $\begin{array}{c}\text { Altitud } \\
\text { (m s.n.m) }\end{array}$ & Coordenadas & $\begin{array}{l}\text { Precipitación } \\
\text { anual (mm) }\end{array}$ & $\begin{array}{c}\text { Temperatura } \\
\text { media máxima } \\
\text { y mínima }\left({ }^{\circ} \mathrm{C}\right)\end{array}$ & $\begin{array}{c}\mathrm{N}^{0} \text { de } \\
\text { estalagmitas } \\
\text { analizadas }\end{array}$ & $\begin{array}{c}\mathrm{N}^{0} \text { de } \\
\text { dataciones } \\
\text { de } \mathrm{U} / \mathrm{Th}\end{array}$ \\
\hline \multirow{3}{*}{$\begin{array}{l}\text { ô } \\
\text { 产 } \\
\text { 音 }\end{array}$} & $\begin{array}{l}\text { EL } \\
\text { Espluca Lasgüériz }\end{array}$ & 1664 & $\begin{array}{c}42^{\circ} 31^{\prime} 59, ' \mathrm{~N} ; \\
0^{\circ} 159^{\prime}, ' \mathrm{E}\end{array}$ & 1090 & $\begin{array}{l}9 \text { máx; } \\
\text {-4 mín }\end{array}$ & $\begin{array}{l}7(+5 \sin \\
\text { resultado })\end{array}$ & 13 \\
\hline & $\begin{array}{l}\text { CT-PF } \\
\text { Pot аи Feu }\end{array}$ & 980 & $\begin{array}{l}42^{\circ} 31^{\prime} 28^{\prime \prime} \mathrm{N} ; \\
0^{\circ} 14^{\prime} 5{ }^{\prime} \mathrm{E} 860\end{array}$ & 860 & $\begin{array}{l}15 \text { máx; } \\
3 \text { mín }\end{array}$ & 4 & 23 \\
\hline & $\begin{array}{l}\text { SE } \\
\text { Seso }\end{array}$ & 640 & $\begin{array}{c}42^{\circ} 24^{\prime} \mathrm{N} ; \\
0^{\circ} 1^{\prime} \mathrm{E}\end{array}$ & $905(*)$ & $\begin{array}{l}21 \text { máx; } \\
6.6 \text { mín (*) }\end{array}$ & 9 & 43 \\
\hline 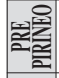 & $\begin{array}{l}\mathrm{EF} \\
\text { Esteban Felipe }\end{array}$ & 900 & $\begin{array}{l}42^{\circ} 19^{\prime} 32^{\prime \prime} \mathrm{N} \\
0^{\circ} 20^{\prime} 47^{\prime}, \mathrm{W}\end{array}$ & 900 & $\begin{array}{l}16 \text { máx; } \\
4 \text { mín }\end{array}$ & 4 & 11 \\
\hline \multirow{5}{*}{ 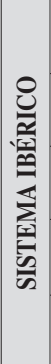 } & $\begin{array}{l}\text { MO } \\
\text { Grutas de Cristal }\end{array}$ & 1040 & $\begin{array}{l}40^{\circ} 47^{\prime} 43^{\prime \prime} \mathrm{N} \\
0^{\circ} 26^{\prime} 58^{\prime \prime} \mathrm{W}\end{array}$ & $420(* *)$ & $\begin{array}{l}19.7 \text { máx; } \\
6.1 \text { mín }(* *)\end{array}$ & 4 & 53 \\
\hline & $\begin{array}{l}\text { ER } \\
\text { El Recuenco }\end{array}$ & 1245 & $\begin{array}{l}40^{\circ} 45^{\prime} 33,94^{\prime \prime} \mathrm{N} \\
0^{\circ} 35^{\prime} 07,39^{\prime \prime} \mathrm{W}\end{array}$ & $420(* *)$ & $\begin{array}{l}19.7 \text { máx; } \\
6.1 \text { mín }(* *)\end{array}$ & 2 & 7 \\
\hline & $\begin{array}{l}\text { LG } \\
\text { La Galiana Baja }\end{array}$ & 990 & $\begin{array}{l}41^{\circ} 43^{\prime} 55,68^{\prime \prime} \mathrm{N} \\
3^{\circ} 02^{\prime} 40,56^{\prime \prime} \mathrm{W}\end{array}$ & $480(*)$ & $\begin{array}{l}10 \text { (media } \\
\text { anual) }(*)\end{array}$ & 2 & 4 \\
\hline & $\begin{array}{l}\text { CR } \\
\text { Sima el Carlista }\end{array}$ & 1087 & $\begin{array}{l}41^{\circ} 45^{\prime} 23,25^{\prime}{ }^{\prime} \mathrm{N} \\
3^{\circ} 04^{\prime} 10,60^{\prime \prime} \mathrm{W}\end{array}$ & $480(*)$ & $\begin{array}{l}10(\text { media } \\
\text { anual) }(*)\end{array}$ & 1 & 2 \\
\hline & $\begin{array}{l}\text { FU } \\
\text { Fuentemolinos }\end{array}$ & 990 & $\begin{array}{l}42^{\circ} 22^{\prime} 30^{\prime \prime}, 94 \mathrm{~N} \\
3^{\circ} 14^{\prime} 42,09^{\prime \prime} \mathrm{W}\end{array}$ & 785 & $\begin{array}{l}17 \text { máx; } \\
7 \text { mín }\end{array}$ & 1 & 2 \\
\hline
\end{tabular}

(*) datos de la red Meteoclimatic (www.meteoclimatic.com): estación de Borrastre (Huesca) para la Cueva de Seso y estación de Hontoria del Pinar para las cuevas de La Galiana Baja y Sima el Carlista.

(**) datos del Embalse de Gallipuén, medias de los últimos 5 años (servidor SAIH de la Cuenca del Ebro; www.saihebro.com).

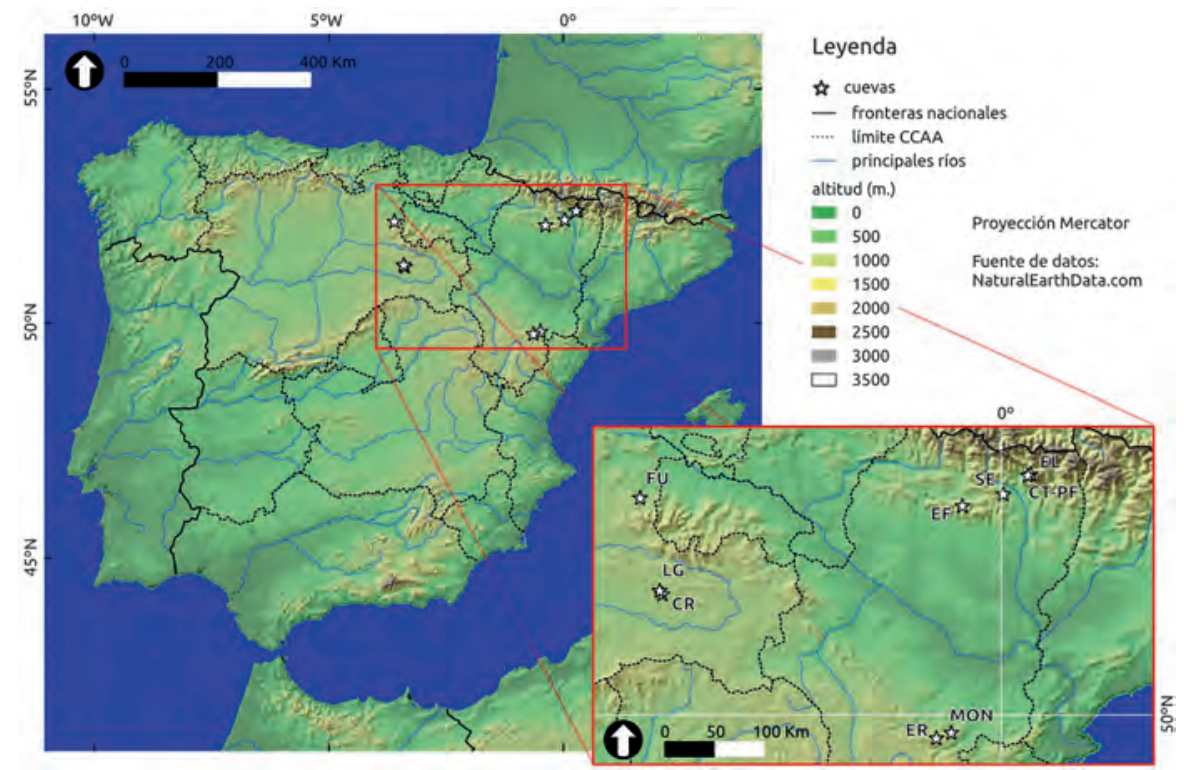

Figura 1. Situación de las cuevas de estudio en el Noreste Peninsular. 


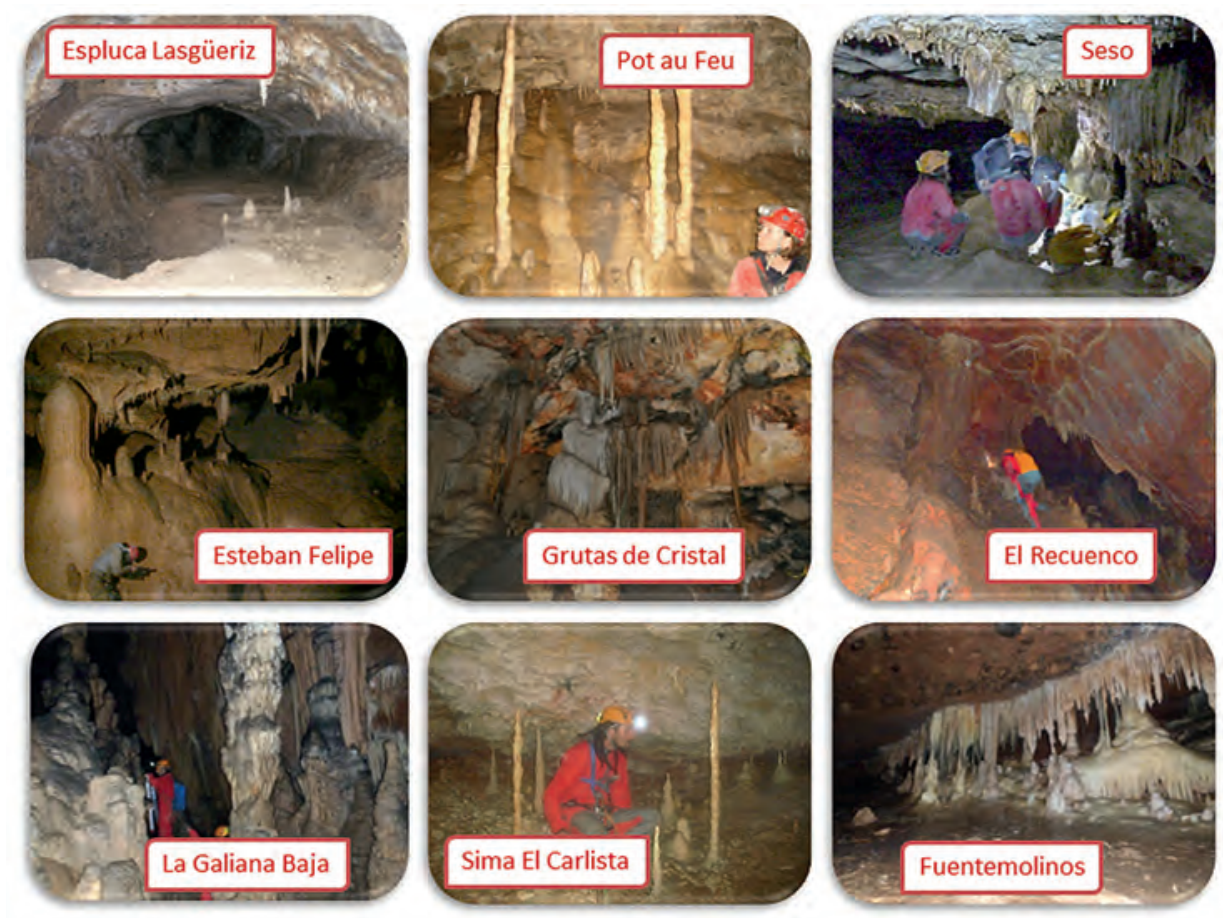

Figura 2. Fotos de las cuevas de estudio donde se aprecian algunas características generales de las cavidades y diferentes tipos de espeleotemas.

contenido de ${ }^{238} \mathrm{U}$ sea suficiente para realizar el análisis, (2), que el sistema haya permanecido cerrado tras la precipitación del carbonato impidiendo posteriores incorporaciones de U o Th y (3), que no haya un importante contenido en Th de origen detrítico (el ${ }^{230} \mathrm{Th}$ suele aparecer asociado normalmente a las arcillas). La primera premisa es necesaria forzosamente ya que si la cantidad de U en la muestra se encuentra por debajo de los límites de detección del espectrómetro será imposible la datación, mientras que la segunda y tercera premisa están más relacionadas con la obtención de la verdadera edad de la muestra, ya que si el sistema ha estado abierto a fuentes de $\mathrm{U}$ o bien, el contenido en detrítico es alto en el carbonato, el error generado puede ser excesivamente elevado.

Las edades de las muestras se obtuvieron en la Universidad de Minnesota (EEUU) (66 dataciones), usando la metodología descrita en Cheng et al. (2009) y mediante un ICP-MS (Thermo-Finnegan ELEMENT) o MC-ICP-MS (Thermo-Finnegan Neptune), y en la Universidad de Melbourne (Australia) (92 dataciones) (Tablas 2 y 3). En la mayoría de las 34 estalagmitas analizadas, las dataciones se realizaron en la muestra basal y terminal para acotar su formación y, cuando se observaron hiatos en dicho crecimiento, se realizaron dataciones para delimitarlos. Esta limitación en muchas de las estalagmitas estudiadas impide que se obtengan con exactitud las tasas de crecimiento, por lo que en este trabajo se presentan solo los periodos con crecimiento de espeleotemas frente a aquellos en los que no se dieron las condiciones idóneas para su formación. 


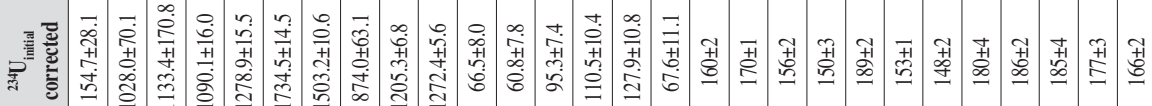

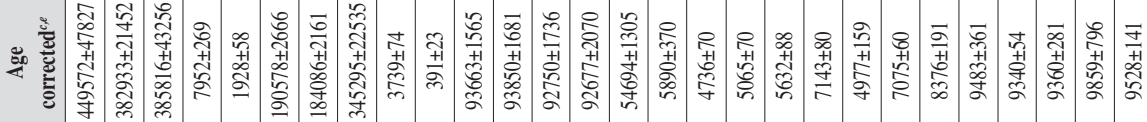

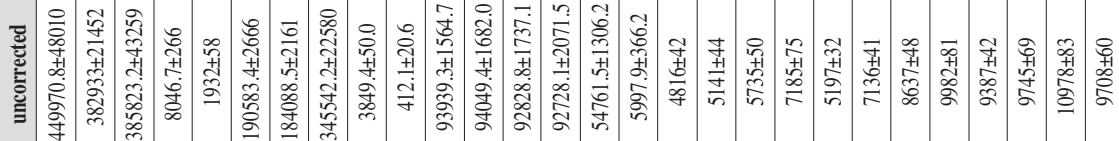

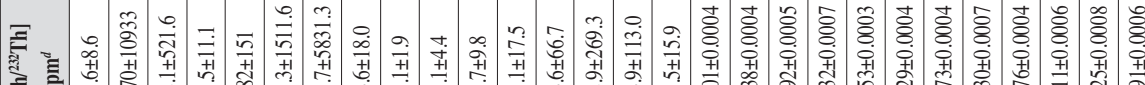

焉

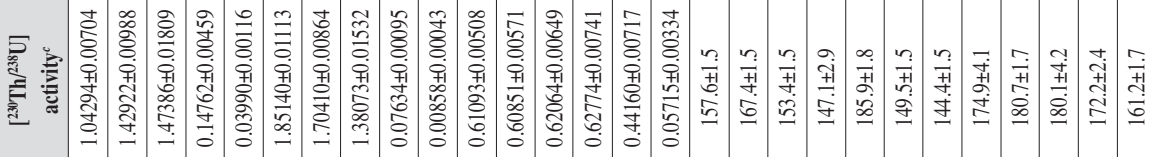

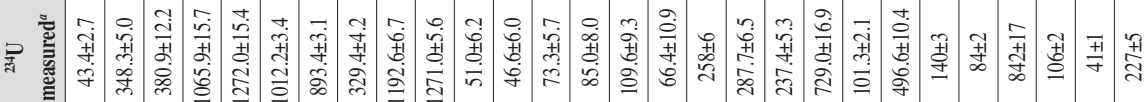

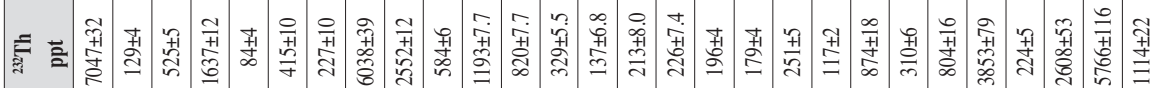

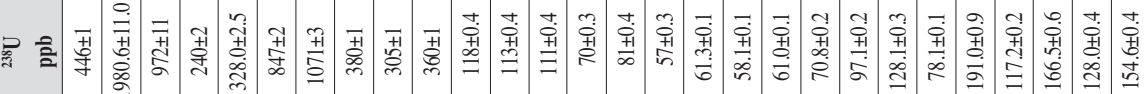

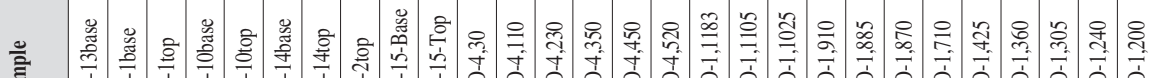

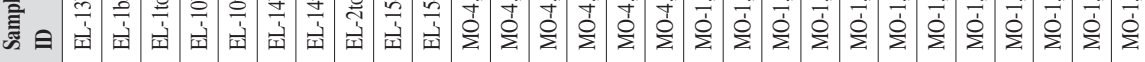

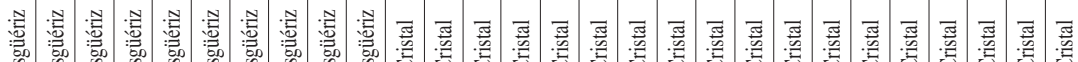

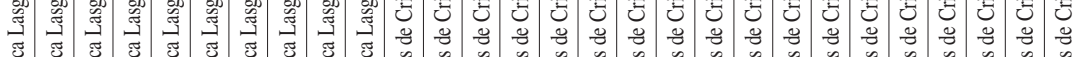

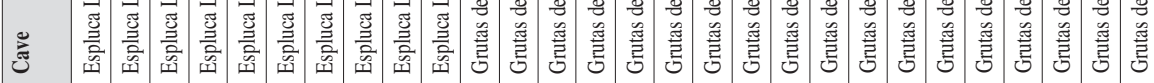




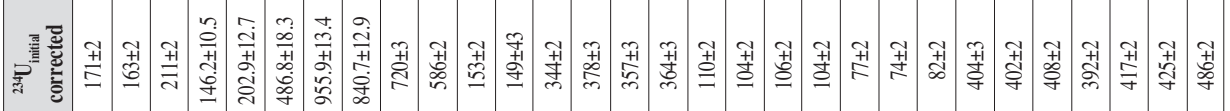

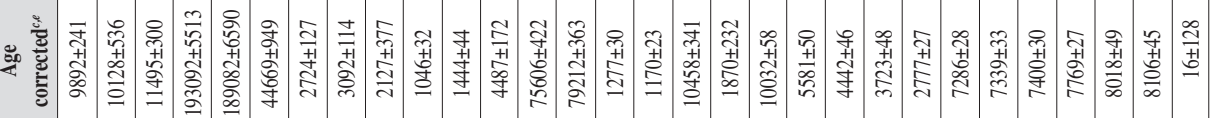

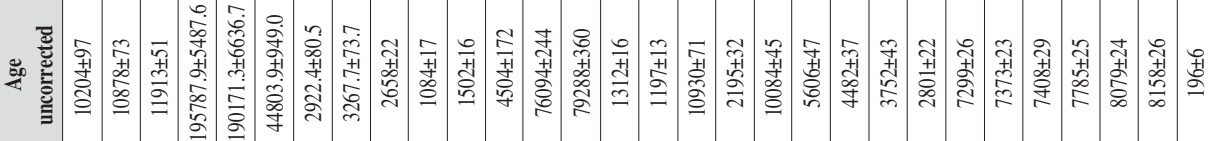

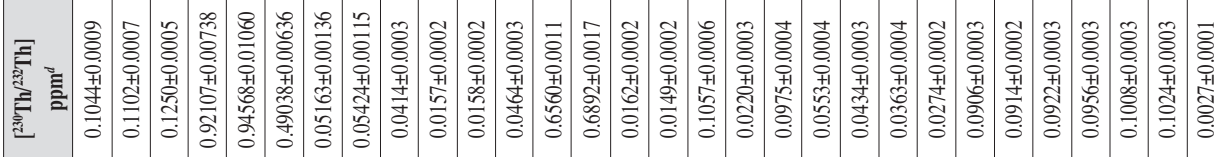

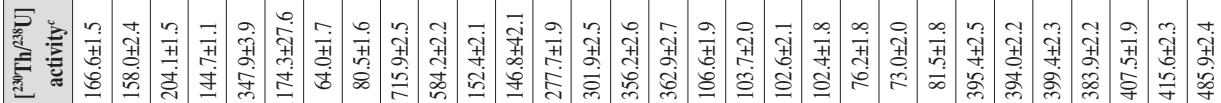

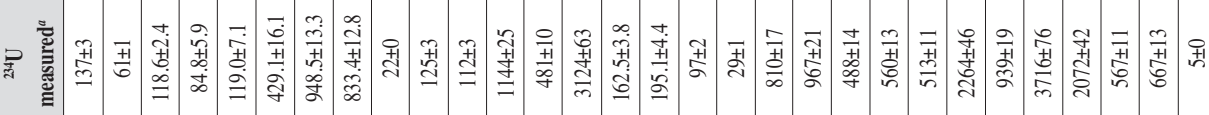

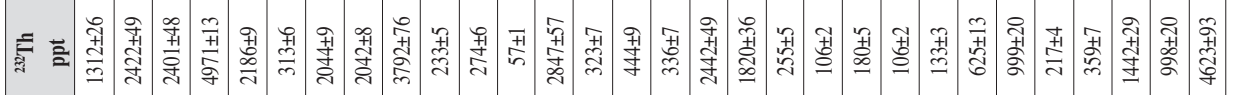

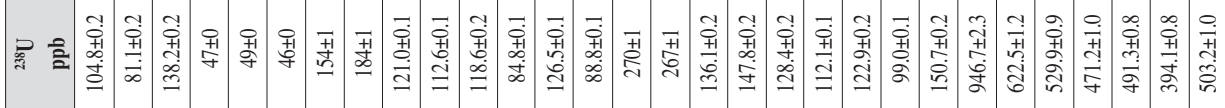

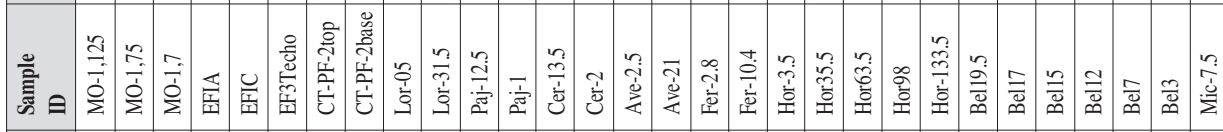

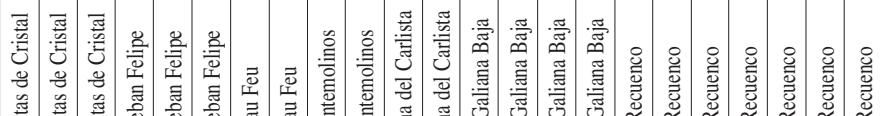

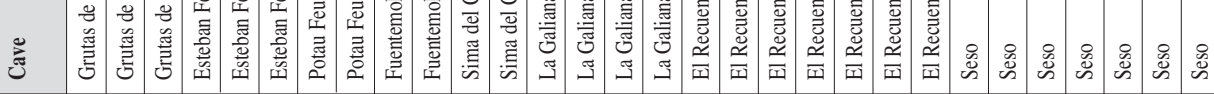




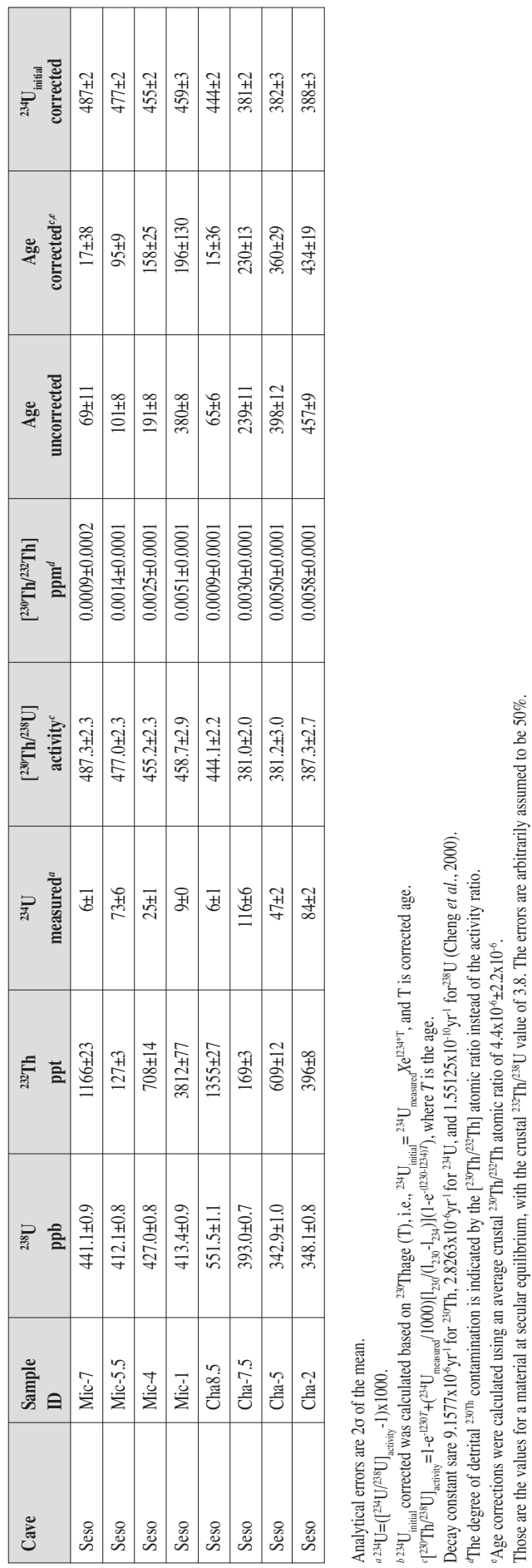




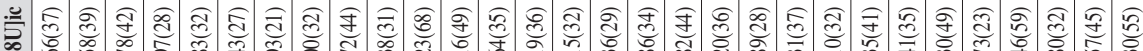

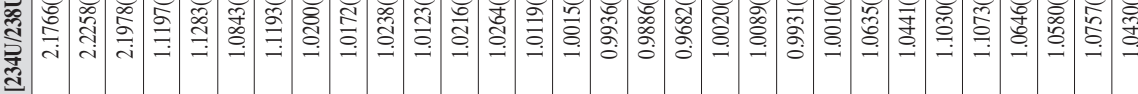

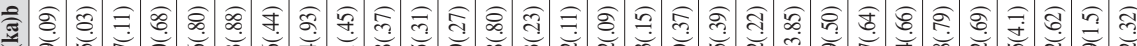
焉

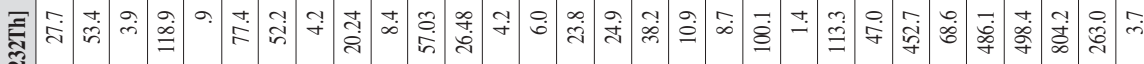

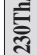

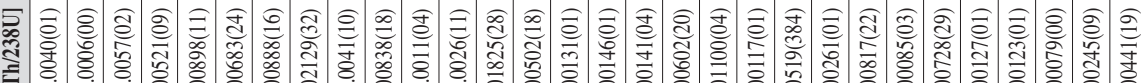

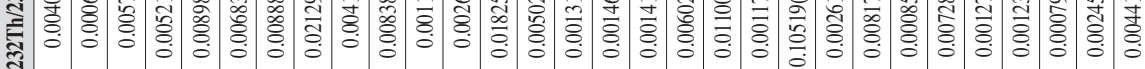

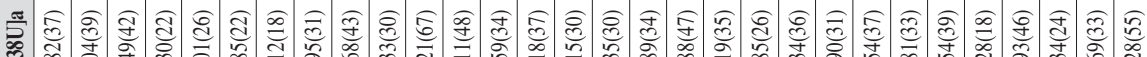

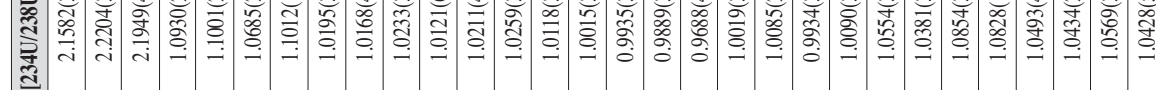

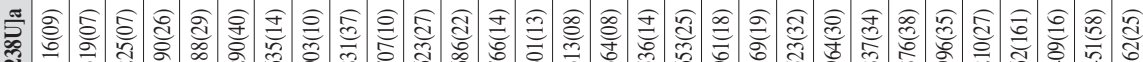

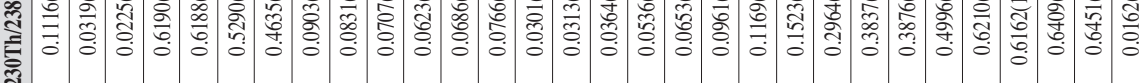
ฮ్

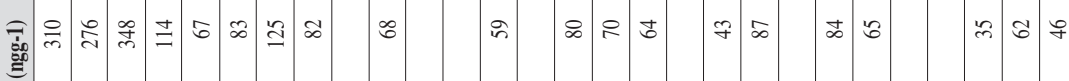

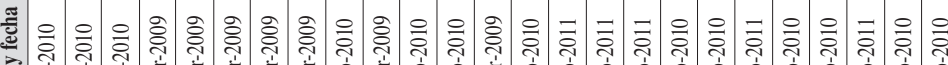

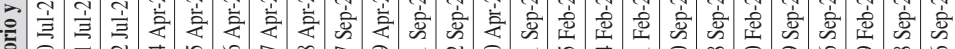

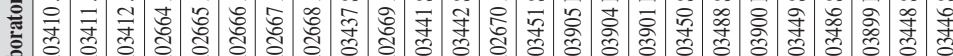

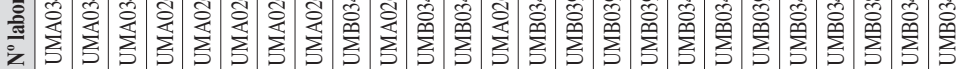

육윻

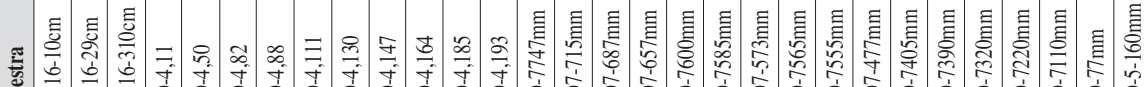

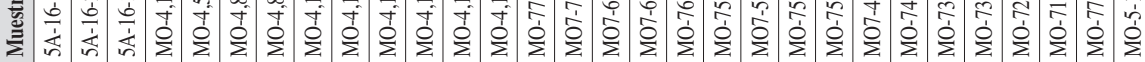

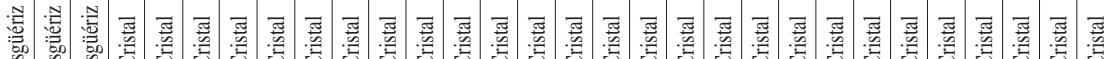

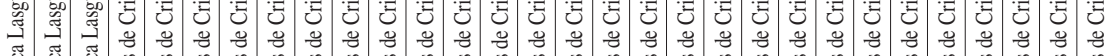

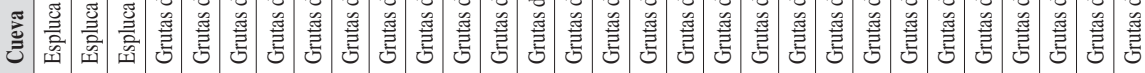




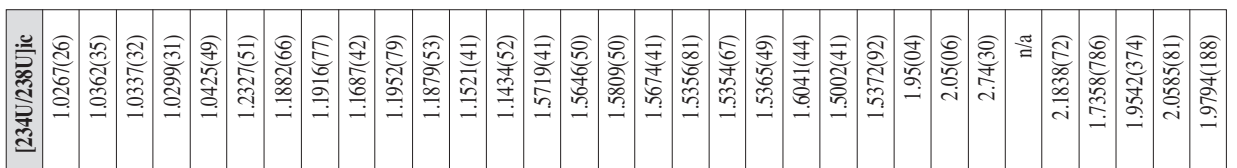

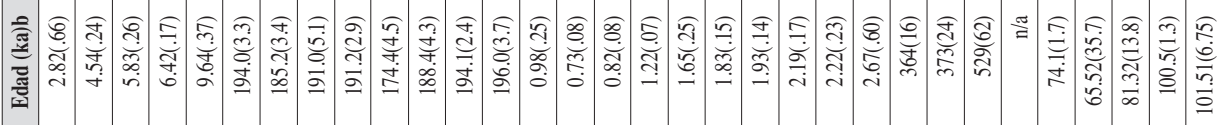

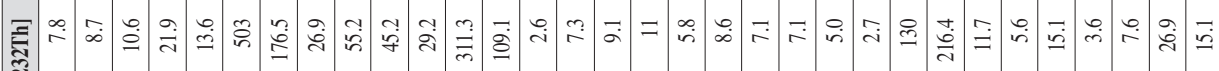

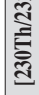

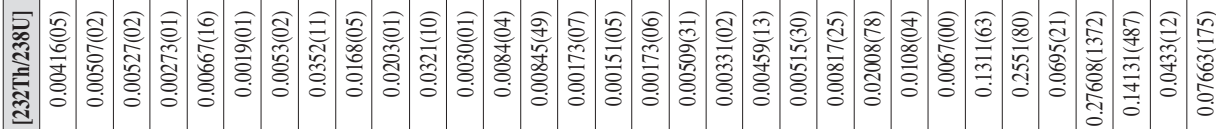

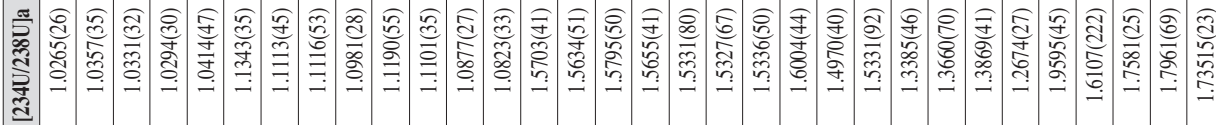

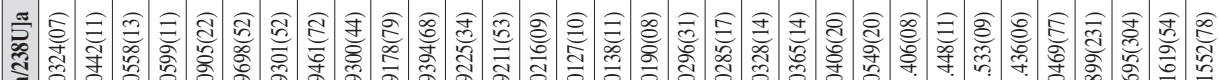
范

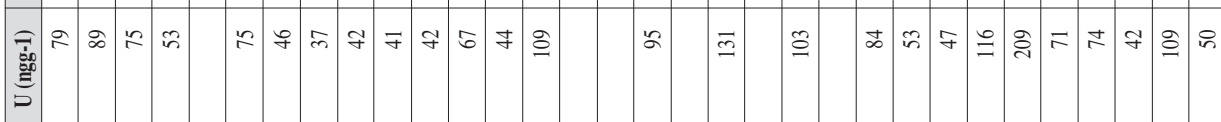

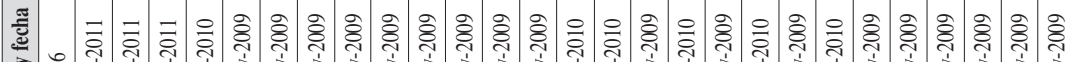

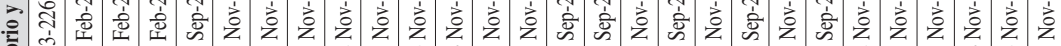

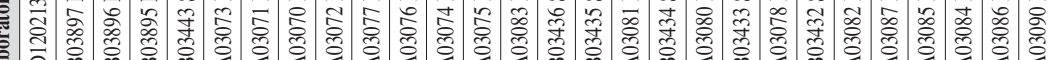

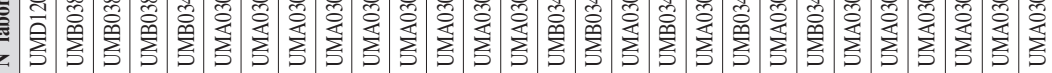

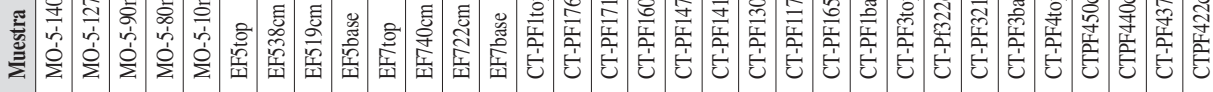

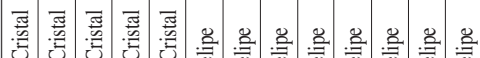

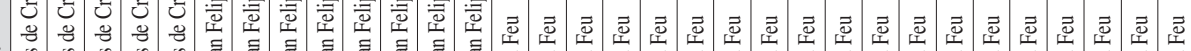

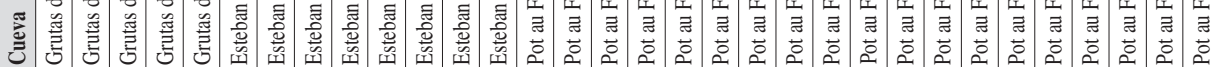




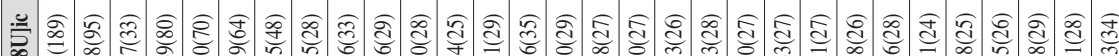

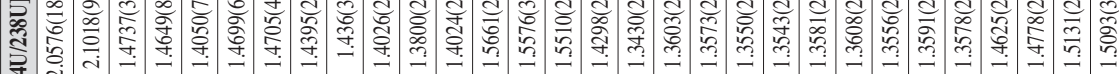
范

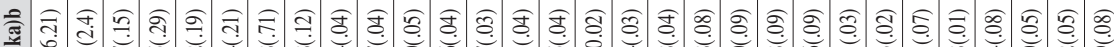

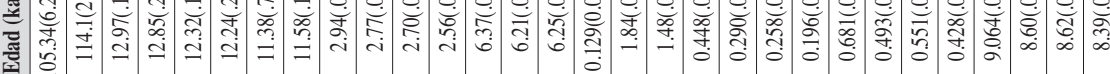

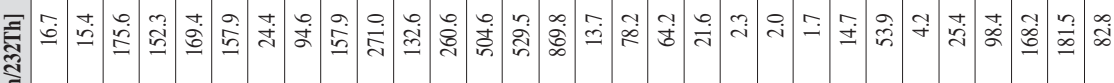

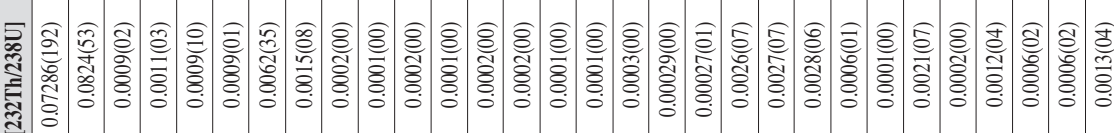

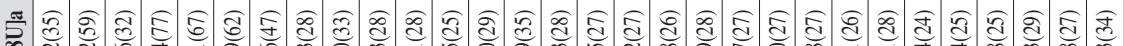

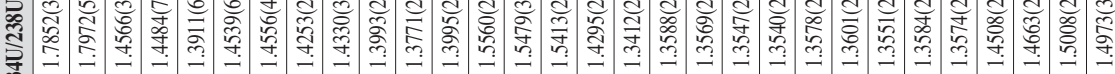

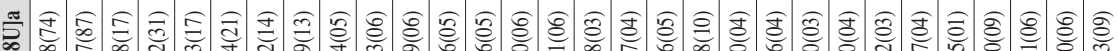

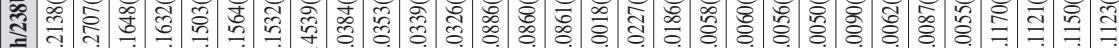
范

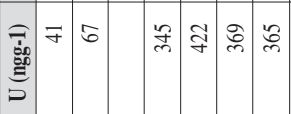

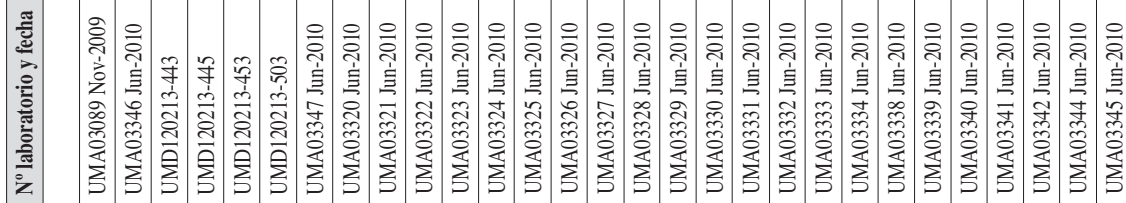

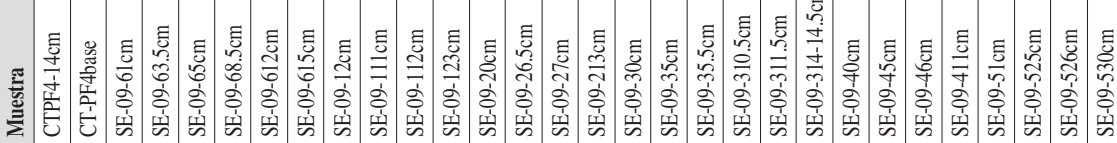

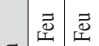

홀

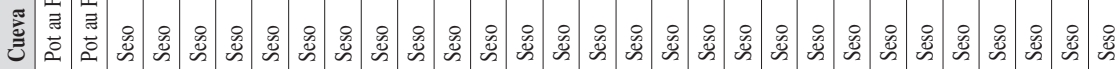

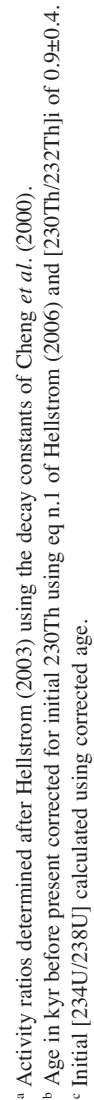




\section{Caracterización de las cavidades}

El macizo de Cotiella se sitúa en el extremo noroccidental de la Unidad Surpirenaica Central y forma parte del gran manto de corrimiento del mismo nombre. Sobre la entrada de La Espluca Alta de Lasgüériz el espesor máximo de calizas es de 600 m (Punta de Lacués, $2286 \mathrm{~m}$ ) y sobre las calizas hay una débil cubierta de suelo con prado de alta montaña. La zona epikárstica está ubicada sobre una extensa superficie de origen estructural, donde se acumularon grandes cantidades de hielo en las fases glaciares. La cavidad está excavada en las calizas con nódulos de sílex de la Fm Baziero (Santoniense) y tiene una longitud de $941 \mathrm{~m}$ y desnivel de $50 \mathrm{~m}$. Morfológicamente se trata de una "watertable cave" (según la clasificación de Ford y Williams, 2007) y corresponde con un gran tubo freático que presenta en numerosos tramos una incisión vadosa de dimensiones métricas, sugiriendo circulación de agua durante largos periodos de tiempo. La Espluca Alta de Lasguiériz es una cueva de escasa ornamentación, donde los espeleotemas más abundantes son las estalactitas, distribuidas siguiendo el trazado de diversas fracturas. Las estalagmitas presentan una gran variedad morfológica con tamaños oscilando entre una decena de centímetros y los casi cuatro metros de la más alta, cuyo diámetro basal está próximo al metro. En muchas zonas de la cueva la base del conducto freático está cubierto por un pavimento calcáreo cuyo espesor medio es de unos $40 \mathrm{~cm}$. Los depósitos detríticos, tanto autóctonos como alóctonos, son abundantes en muchos sectores de la cavidad.

Dentro del mismo macizo de Cotiella, pero a menor altitud se localiza la cavidad Pot au Feu en el Valle del Irués a 997 m s.n.m., desarrollándose en el núcleo del anticlinal de Baquerizal. Se trata de una zona fuertemente tectonizada donde alternan escamas de calizas y margas cretácicas y calizas terciarias, próximas a la base del manto de Cotiella. En el exterior de la cavidad se observa un relieve escalonado de origen estructural. La vertical de la cavidad está constituida por los llanos de Napinals, a $1550 \mathrm{~m}$ de altitud, cubiertos por prado y bosques de pino negro. La cueva está en proceso de exploración y topografía. Se encuentra sobre el nivel activo del sistema de drenaje del macizo de Cotiella, formado por las surgencias de Fornos y los trop-pleins del Chorro y Graners. El interior del Pot au Feu presenta una sucesión de loops donde se alternan tubos de circulación forzada de distintos diámetros, ascendentes y descendentes, con cortos tramos horizontales y salas de pequeño tamaño. Algunas de estas salas están muy ornamentadas, con estalagmitas de hasta $1.5 \mathrm{~m}$ de altura y $25 \mathrm{~cm}$ de diámetro. La ausencia de sedimentos detríticos es casi general, a excepción de algunos niveles de finos de tipo slack-water. La preservación de numerosas estalactitas excéntricas en salas de cotas bajas indica que la cavidad ya no se inunda.

También en la comarca del Sobrarbe, en el Pirineo Central, pero más al sur y a menor altitud que las cuevas anteriores, se localiza la cueva de Seso, en las cercanías de la población de Boltaña (Huesca). Dicha cavidad se desarrolla en los materiales calcáreos del flanco Este del anticlinal de Boltaña, el cual forma el límite estructural entre la Cuenca de Jaca y la Unidad Surpirenaica Central (Soto y Casas, 2001). La cueva se encuentra en la Fm Boltaña (Eoceno inf.), compuesta por una alternancia de margas y calizas con foraminíferos. Se trata de una cueva pequeña (250 m de desarrollo), con un desnivel ascendente máximo de 40 m (Mas y Fuertes, 2007) y muy superficial, ya que 
solo la separa de la superficie una capa caliza con espesor máximo de $2 \mathrm{~m}$. Como peculiaridad, la cueva se desarrolla en un estrato margoso limitado a base y techo por capas calizas y su espeleogénesis se produjo debido al transporte mecánico de la marga por el agua de infiltración a través de la fractura principal que controla la dirección de la cueva (Bartolomé et al., 2013). Se trata de una cueva activa desde el punto de vista espeleotémico y en su interior aparecen gran variedad de formas espelotémicas: gours, que tapizan la base de la cavidad, estalagmitas, estalactitas y coladas. Su tamaño y abundancia varían, diferenciándose claramente dos fases importantes de desarrollo estalagmítico. Sobre parte de la cueva aparece desarrollado un suelo tipo calcisol cámbico que soporta un bosque de pinos, encinas y matorral.

Al sur de las anteriores cavidades, y dentro del Parque Natural de la Sierra y Cañones de Guara (Huesca), se encuentra la sima Esteban Felipe. La entrada está a 1030 m s.n.m. y está excavada en la formación calizas de Guara (Luteciense), entre los anticlinales de Gabardiella y el Águila (Millán, 2006) dentro de las Sierras Exteriores pirenaicas. Su desarrollo se produce en el dorso de un relieve en cuesta que cae desde el escarpe de Zienfuens hacia el vaso del embalse de Belsué, que aprovecha las margas de Arguis como impermeable. La cavidad tiene más de $1850 \mathrm{~m}$ de recorrido y una profundidad máxima de $123 \mathrm{~m}$, estructurados en tres niveles horizontales principales unidos por diversos pozos. La ornamentación de la cavidad es abundante encontrándose multitud de tipos de espeleotemas, algunos ligados a la presencia -actual o pasada- de acumulaciones de agua permanentes (perlas, platos, etc.). El nivel superior está separado de la superficie por una capa de potencia inferior a cuatro metros y es allí donde se concentra la mayor parte de las estalagmitas. Dado que se trata de una cavidad fósil, la presencia de agua está condicionada a las filtraciones tras épocas de lluvia y al deshielo.

Las Grutas de Cristal o Cueva de las Graderas (Molinos, Teruel) se encuentran en la Cuenca del Maestrazgo, en la denominada Zona de Enlace entre la Cordillera Costera Catalana y el sector oriental de la Cordillera Ibérica. La cavidad, formada en calizas cretácicas del Cenomaniense-Turoniense, consta de dos galerías horizontales conectadas y un total de $620 \mathrm{~m}$ de desarrollo. Actualmente hay muy poco desarrollo edáfico sobre la cueva y el espesor de roca es también reducido por lo que la infiltración del agua de lluvia ocurre rápidamente. Esta cueva es unas de las pocas cuevas en Aragón habilitadas para el turismo y es conocida por sus espectaculares formaciones de espeleotemas, especialmente por la profusión de excéntricas. Aunque aparece una excelente ornamentación espeleotémica, es posible observar también rasgos erosivos a techo de la cavidad asociados con una fase freática anterior. Las formaciones mejor representadas son coladas parietales, coladas pavimentarias, gours, estalagmitas, excéntricas, estalactitas, coraloides y moonmilk.

A tan solo $10 \mathrm{~km}$ al suroeste, se encuentra la cueva de El Recuenco, situada en las proximidades de la localidad de Ejulve (Teruel), concretamente en lo alto del monte Malajinos. La cavidad se desarrolla en los materiales dolomíticos y evaporíticos de la Fm Cortes de Tajuña (límite Triásico-Jurásico inf.), compuesta por un amplio abanico de facies: brechas dolomíticas y evaporíticas, ruditas poligénicas, algales, entre otras muchas (Bordonaba y Aurell, 2001), pero en general se caracteriza por su elevada poro- 
sidad y facilidad de formación de cavidades en ella a escala regional. Se trata de una cueva de escasas dimensiones en la que se alternan grandes salas con estrechos pasos y no se observa un patrón claro de desarrollo de galerías. La presencia de grandes bloques de roca caja en su interior sugieren que su espeleogénesis pudo estar relacionada con una disolución progresiva de las brechas evaporíticas provocando colapsos en diversas zonas para finalmente conformar la cueva. En su interior se observan gran cantidad de depósitos internos clásticos (acumulaciones de bloques principalmente) y químicos (estalagmitas, estalactitas y esporádicamente gours). Se observan numerosas zonas con carbonato de aspecto actual, lo que refleja una alta actividad química de las aguas. Sobre la cueva se desarrolla un escaso suelo que alberga matorral principalmente y pequeños pinos y encinas.

En el extremo opuesto de la Cordillera Ibérica, se encuentran las cuevas de la Galiana Baja y la Sima del Carlista, ambas en el Parque Natural del Cañón del Río Lobos y la Cueva de Fuentemolinos, al pie de la Sierra de la Demanda. La Cueva de la Galiana Baja se encuentra en las proximidades de la población de Ucero (Soria) y se trata de la cavidad con mayor desarrollo horizontal de la provincia de Soria con casi $1600 \mathrm{~m}$. Se abre en una serie horizontal de calizas nodulosas de edad Coniaciense (Cretácico sup.) con una fracturación principal NO-SE. La cueva forma, junto a las cuevas de la Galiana Alta I y la Galiana Alta II, un sistema de conductos horizontales a diferentes niveles respecto al cauce, que funcionaron primero como conductos de circulación forzada y posteriormente vadosa, y que fueron abandonados según se produjo el avance del encajamiento de los ríos Lobos y Ucero. En su interior existe una gran profusión de espeleotemas, destacando la zona de "El bosque" donde las estalagmitas adquieren su mayor desarrollo. Por otro lado, la actividad química de las aguas queda reflejada en las numerosas zonas de actual precipitación de carbonato. También son abundantes las zonas de acumulación de bloques debido a colapsos parciales de la cavidad además de varios niveles de encajamiento y de paleolagos preservados. La Sima de El Carlista es la cueva con mayor desarrollo vertical de la provincia de Soria con $-124 \mathrm{~m}$ de desnivel. La cueva, al igual que la Galiana Baja, se abre en las calizas coniacienses del Cretácico superior y consta de dos partes bien diferenciadas: un primer nivel superficial de desarrollo horizontal, seguido de un gran pozo de $90 \mathrm{~m}$ hasta alcanzar la base de un segundo nivel, que da paso a una gran sala a $100 \mathrm{~m}$ de profundidad. La cota más profunda corresponde con unas pequeñas galerías semi-verticales inundadas en las que su nivel varía según el caudal del río Lobos. La parte superior de la cueva se caracteriza por presentar un menor desarrollo espeleotémico, que está formado por grandes estalagmitas de aspecto antiguo y parcialmente alteradas. En la zona más profunda de la cavidad es donde se localiza el mayor desarrollo espeleotémico y donde presentan un aspecto más reciente.

Por último, la Cueva Fuentemolinos se encuentra en las proximidades de la población de Puras de Villafranca (Burgos). Su característica principal es su desarrollo en conglomerados polimícticos del tránsito Oligoceno-Mioceno (Terciario) procedentes principalmente de los materiales paleozoicos de la Sierra de la Demanda. La cavidad cuenta con dos niveles bien diferenciados; uno activo por el cual circula un río, aunque también se encuentran pequeñas zonas fósiles con gran profusión de espeleotemas, y un 
nivel fósil superior, donde los espeleotemas son especialmente abundantes. También se observan numerosas acumulaciones de gravas cementadas por carbonato a diferentes alturas en ambos niveles y zonas con precipitación actual de carbonato.

\section{Resultados y Discusión}

Casi todas las muestras de espeleotemas analizadas presentan un crecimiento corto en el tiempo, a veces discontinuo, y en general asociado con un periodo interglaciar (Tabla 2, Fig. 3). La diferente situación altitudinal de las cuevas estudiadas permite observar patrones ligeramente distintos en cuanto a los periodos de formación de espeleotemas que pueden asociarse a las diferentes condiciones climáticas. Por ejemplo, las estalagmitas de Espluca Lasgüériz, la cueva de mayor altitud y situada bajo un clima más frío (temperatura media anual de $5^{\circ} \mathrm{C}$ ), presentan tasas de crecimiento muy lentas incluso en el Holoceno (ej. un centímetro cada 1000 años, estalagmitas EL-10, EL-15 y EL-16). Estos crecimientos tan limitados se asocian al escaso goteo en la cueva y/o a la probablemente escasa capacidad del agua de disolver carbonato por las bajas concentraciones en $\mathrm{CO}_{2}$ esperables en un sistema con escaso desarrollo edáfico y nula cubierta vegetal. Por lo tanto, el agua de goteo que entraría en la cueva, además de ocurrir solamente en periodos cálidos y relativamente húmedos como los interglaciares (Fig. 3), está escasamente saturada y produce muy poca precipitación de carbonato. Durante los estadios isotópicos glaciares, por encima de $2100 \mathrm{~m}$, la superficie estaría ocupada por un glaciar o bajo condiciones de permafrost permanente. Ambas situaciones impedirían la disponibilidad de agua en estado líquido, al igual que en otras cuevas de los Alpes (Spötl et al., 2005).

Además, en Espluca Lasgüériz hay crecimientos intermitentes en el MIS7 (en concreto, en el MIS7a, estalagmita EL-14) y en los estadios MIS9-11 (muestras EL-1, EL-2 y EL-13). Este crecimiento más antiguo es difícil de situar con exactitud en el tiempo por el alto error de las muestras analizadas (Tabla 2), pero el cluster obtenido entre esas tres muestras de Espluca Lasgüériz y una muestra más, proveniente de la cercana cueva Pot au Feu (PF-3), parece indicar que el intervalo temporal más favorable a la formación de espeleotemas se produjo entre los 350-400 ka (MIS10-MIS11). El que las estalagmitas de estas dos cuevas no aparezcan claramente asociadas al MIS11, interglaciar que se ha considerado por algunos autores como un análogo al actual Holoceno (Herold et al. 2012), puede deberse a varios factores. Por un lado, hay que destacar los amplios márgenes de error en las dataciones y el escaso número de muestras analizadas en ese periodo (cuatro estalagmitas). Sin embargo, por otro lado, el hecho de que no haya cambios abruptos entre MIS11 y MIS10 (ver SST del margen portugués y la curva SPECMAP en Fig. 3) nos permite pensar que quizás las estalagmitas que empezaron a crecer en MIS11 (ej. base de EL-13 y muestras EL-1 y PF-3) pudieron continuar su crecimiento durante algunos milenios del MIS 10 interrumpiéndose hacia 340 ka cuando se alcanzan los valores mínimos de SST del MIS10 (ej. techo de EL-2).

El crecimiento de la estalagmita EL-14 de Espluca Lasgüériz ocurre centrado en el MIS7a (210-180 ka), y de nuevo asociado a una tasa de crecimiento lenta (500 años por centímetro), pero que es doble de la obtenida en las muestras Holocenas (1000 años 
por centímetro). Este periodo (MIS 7a) está también representado en tres estalagmitas más de la Sierra de Guara (sima Esteban Felipe) por lo que aparece como uno de los intervalos óptimos para el crecimiento espeleotémico en el Noreste peninsular. El MIS7a, como se observa en la curva SPECMAP, es el momento de clima más benigno del MIS7 por lo que parece razonable esperar un clima favorable a la precipitación de carbonato en la cueva, con desarrollo edáfico importante incluso a $2000 \mathrm{~m}$ de altitud, temperaturas como las actuales o ligeramente superiores y suficiente disponibilidad hídrica. Sorprendentemente, este patrón de crecimiento espeleotémico asociado a interglaciares no se observa durante el MIS5 en Espluca Lasgüériz aunque es cierto que el número de muestras investigadas en esa cueva (12 espeleotemas) puede no ser suficiente para descartar la precipitación de carbonato durante el anterior interglacial (periodo MIS5e, Eemiense) (Shackleton et al., 2003). Por el contrario, sí que hay representación del MIS5 en Pot au Feu (PF-4), la otra cueva del macizo de Cotiella también bajo condiciones climáticas frías, aunque localizada a menor altitud.

El crecimiento de la estalagmita PF-4 durante el MIS5 (Fig. 3) presenta tres características significativas, que se reflejan también en otras muestras de cuevas de menor altitud: (1) comienza su crecimiento a $115 \mathrm{ka}$, varios milenios después del inicio del interglaciar MIS5e, (2) deja de crecer al inicio del MIS4 (aprox. 70-75 ka) y (3) las máximas tasas de crecimiento se alcanzan a los 100-110 ka (aproximadamente 200-300 años por centímetro). El retraso en la formación del espeleotema respecto al inicio del MIS5e puede ser debido a que la actividad periglaciar es más persistente a la altura de la cueva y la temperatura y la disponibilidad hídrica no alcanzan los valores idóneos para la formación de espeleotemas hasta más tarde. Hay que tener en cuenta que la fase glaciar anterior a este estadio, correspondiente al MIS6, se ha caracterizado en otros valles del Pirineo por una gran extensión de los glaciares (ej. Sabiñánigo a 155 ka, Peña et al., 2004) por lo que cabe esperar que a la altitud de las cuevas estudiadas, los glaciares permanecieran durante más tiempo o, al menos, las condiciones de permafrost perduraran varios milenios, retrasando el inicio del crecimiento de espeleotemas hasta las siguientes fases cálidas del MIS5 (MIS5c o el MIS5a). Las únicas dos estalagmitas que también crecen en el MIS5 del total de 34 muestras estudiadas, tampoco lo hacen desde su inicio (MIS5e) sino que empiezan a crecer varios milenios más tarde. Esas dos estalagmitas son MO-7 y MO-4 de las Grutas de Cristal (en Molinos, Teruel) donde también, probablemente, las condiciones óptimas se alcanzaron más tarde. En este caso, dado que la temperatura no parece ser el factor clave en la zona, se baraja como hipótesis que la humedad necesaria para el desarrollo edáfico y de vegetación en la zona ocurrió hace 110-100 ka, coincidiendo con las máximas tasas de crecimiento en el Pirineo, como se ha observado en PF-4.

El periodo con mayor tasa de crecimiento en PF-4, ligado a 110-100 ka, y que es además cuando empieza el crecimiento espeleotémico en las Grutas de Cristal, se puede relacionar con el estadio MIS5c, periodo cálido que corresponde con un máximo de insolación de verano (Fig. 3). Realmente, esta fase de rápido crecimiento en el MIS5, sería el momento de mayor precipitación de carbonato en las cuevas pirenaicas (Espluca Lasgüériz y Pot au Feu), con tasas mayores que durante el MIS7a y el MIS11-10 y también uno de los periodos más importantes de formación de espeleotemas (tan solo detrás del Holoceno) en las Grutas de Cristal. La explicación más plausible a este máximo desarro- 


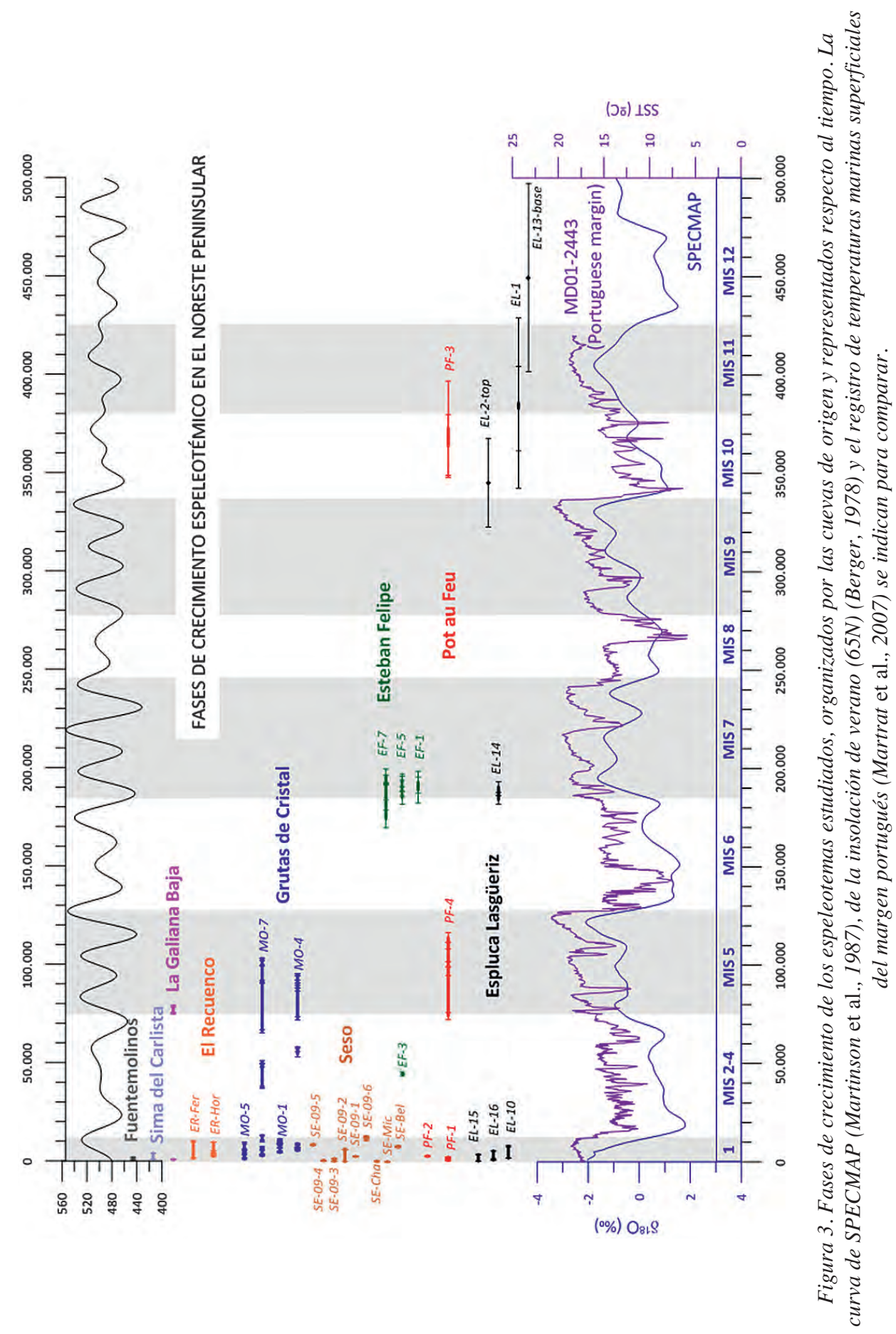


llo espeleotémico en zonas tan alejadas se apoya en el aumento de humedad inferido en depósitos fluviales (Benito et al., 2010; Fuller et al., 1998). Contrariamente a esta hipótesis, en el cañón del Trabaque, también localizado en el Sistema Ibérico, las mayores tasas de depósito de tufas se obtienen para el MIS5e (Domínguez-Villar et al., 2011). Sin duda, más registros bien datados son necesarios para confirmar qué periodo del MIS5 fue más húmedo y, por tanto, más favorable para la formación de tufas y espeleotemas.

La interrupción del crecimiento de PF-4 está claramente ligada a la entrada en el MIS4, periodo frío caracterizado por nuevos avances glaciares en el Pirineo. En concreto, es durante el MIS4 cuando se localizan los depósitos glaciares (y los fluviales asociados) más extensos (Lewis et al., 2009; Peña et al., 2003). El comienzo del MIS4 también fuerza la interrupción de otras estalagmitas que estaban creciendo durante el MIS 5 en otros sistemas kársticos no ligados a sistemas glaciares. Así, en un sistema kárstico completamente distinto y alejado como es el de la cueva de La Galiana Baja en el Cañón del Río Lobos, también se observa la interrupción de una estalagmita con el inicio del MIS4, apoyando que ese intervalo temporal estuvo caracterizado por climas fríos y secos en el Noreste peninsular. Similarmente pero al otro lado del Sistema Ibérico, MO4 y MO-7 de las Grutas de Cristal de Molinos también experimentan una interrupción en su crecimiento que dura, respectivamente, de los 73-58 ka y de 66.5-51 ka. Con la incertidumbre asociada a las dataciones, esas fechas se pueden considerar en clara relación con el periodo MIS4 que probablemente fue especialmente frío en el Noreste peninsular y quizás árido en el Sistema Ibérico.

Durante el MIS3 solo hay crecimientos breves de espeleotemas y en las cuevas de menor altitud de Sierra de Guara y Sistema Ibérico. En las dos cuevas del Macizo de Cotiella no se han registrado espeleotemas desde 75 ka hasta la entrada al Holoceno, probablemente porque permanecieron a temperaturas tan frías que impidieron la precipitación de carbonatos. Así, como se observa en la Fig. 3 y Tabla 2, en las Grutas de Cristal de Molinos hay crecimientos entre 58-54 ka y entre 50.8 y $37.8 \mathrm{ka}$, correspondiendo con el intervalo más cálido del estadio isotópico, aunque también punteado por cambios climáticos rápidos como los eventos de Heinrich y los ciclos de Dansgaard-Oeschger. Además, hay otra estalagmita en Esteban Felipe (EF-3) con un crecimiento muy corto en torno a los $44 \mathrm{ka}$. Posteriormente, después de unos $35 \mathrm{ka}$, ya no hay crecimiento de espeleotemas hasta la última deglaciación (tan solo dos muestras: SE-09-6 de Seso que se forma durante el Younger Dryas y MO-7 de las Grutas de Cristal que crece entre 13.4-10.6 ka), indicando que casi todo el MIS3 y el MIS2 son periodos poco favorables para la formación de estalagmitas tanto en las cuevas del Pirineo, como en la Sierra de Guara o en el Sistema Ibérico. De un modo similar, en un estudio reciente de las tasas de crecimiento de estalagmitas de cuevas asturianas se ha observado que durante el MIS3 el crecimiento es episódico y ocurre en breves intervalos a $41 \mathrm{ka}, 36.5$ y $28.6 \mathrm{ka}$, todos coincidentes con las fases cálidas de los ciclos de Dansgaard-Oschger (Stoll et al., en prensa). Probablemente, el MIS3-2 fue un periodo demasiado frío y árido, además de muy inestable, como atestiguan otros registros de espeleotemas (Moreno et al., 2010), secuencias lacustres (Moreno et al., 2012) y depósitos glaciares (Lewis et al., 2009; García-Ruíz et al., 2010) del Noreste peninsular. Las condiciones de mayor humedad parecen reestablecerse durante el YD, tal y como se deduce de registros fluviales y aluviales, tanto en Pirineos (Lewis et al., 


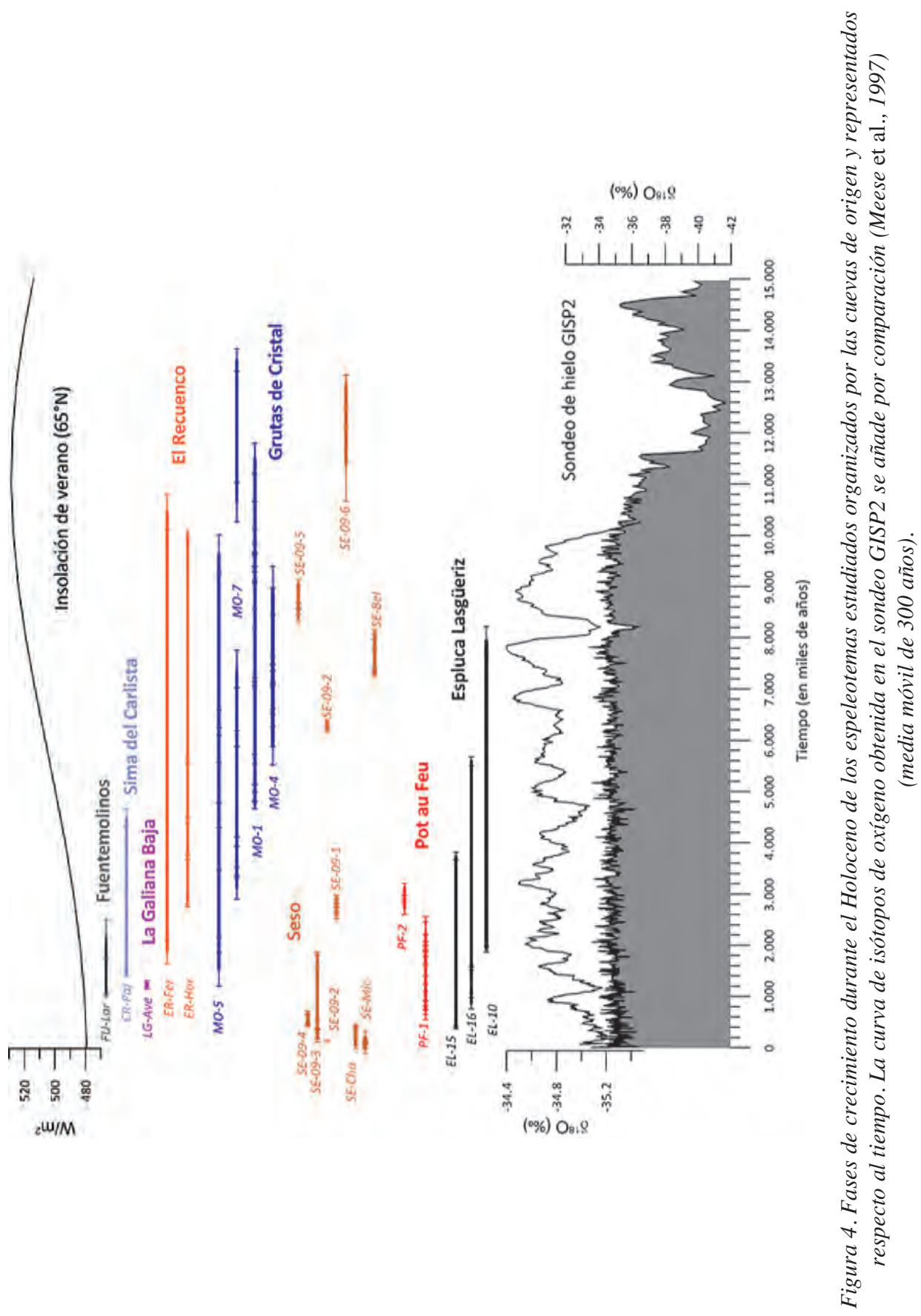


2009), como en la Cordillera Ibérica (Fuller et al., 1998) No es hasta el Holoceno cuando se producen de manera generalizada nuevos crecimientos de espeleotemas.

El presente interglacial, el Holoceno, es el periodo mejor representado en cuanto a crecimiento de espeleotemas en todas las cuevas de estudio salvo en Esteban Felipe (Fig. 4). Del total de 34 muestras estudiadas, 23 pertenecen al Holoceno. Este crecimiento ocurre a diferentes velocidades, dependiendo de la muestra y de la cueva y, aunque en general es un crecimiento bastante continuo (ej. hay cuatro estalagmitas en las Grutas de Cristal que cubren prácticamente todo el Holoceno), hay algunos periodos poco representados. Por ejemplo, en las cuevas del Sistema Ibérico no hay crecimiento espeleotémico durante los últimos 1-2 ka indicando que los últimos siglos han sido más secos que el resto del Holoceno. Sin embargo en la cueva de Seso (y en menor medida en las otras dos cuevas pirenaicas) sí que hay espeleotemas formados en los últimos cientos de años reflejando una mayor disponibilidad hídrica y, probablemente, una buena cubierta vegetal y desarrollo edáfico. Por otro lado, conviene destacar que el crecimiento de espeleotemas en la cueva de Seso es muy sensible a los cambios climáticos, formándose sólo espeleotemas en momentos muy determinados caracterizados por una mayor disponibilidad hídrica (Bartolomé, 2011). Esta diferenciación entre cuevas del Pirineo y del Sistema Ibérico permite plantear la hipótesis de que la sequía de los últimos siglos, analizada en el contexto de todo el Holoceno, está más relacionada con las lluvias de carácter Mediterráneo, que son un porcentaje de la lluvia total más importante en el Sistema Ibérico que en el Pirineo, que con la entrada de frentes Atlánticos. Esta hipótesis será explorada en mayor profundidad con nuevas muestras y a través de la composición isotópica de varias estalagmitas.

\section{Conclusiones}

El crecimiento de espeleotemas, especialmente en las cuevas de altitud del macizo de Cotiella, es discontinuo, lento y limitado a periodos interglaciares. El MIS7, en concreto el MIS7a, aparece como el intervalo temporal más favorable para el crecimiento espeleotémico en el Noreste peninsular, exceptuando el Holoceno donde el desarrollo de espeleotemas es mayor en todas las cuevas estudiadas.

El crecimiento de espeleotemas durante el MIS5 comienza varios milenios después del Eemiense (MIS5e) quizás debido a que la actividad periglaciar impide la formación de espeleotemas en las cuevas de altura (Pot au Feu) o la baja disponibilidad hídrica en las cuevas de menor altitud (Grutas de Cristal). El periodo con crecimientos más rápidos en el MIS5 se sitúa entre 100-110 ka, coincidiendo con un máximo en la insolación de verano.

La entrada al MIS4 fuerza la ralentización o parada del crecimiento de espeleotemas en cuevas pirenaicas y del Sistema Ibérico. Dicha fase sin formación de espeleotemas se prolonga hasta el Holoceno, salvo crecimientos muy puntuales en el MIS3 y en la deglaciación y solo en las cuevas situadas bajo la influencia de climas menos extremos.

Durante el Holoceno, el desarrollo espeleótemico es generalizado en el Noreste peninsular, si bien presenta un comportamiento diferencial de Pirineos a Cordillera Ibérica relacionado con el régimen de precipitaciones dominante en cada zona. 


\section{Agradecimientos}

Este estudio se ha financiado principalmente gracias a los proyectos regionales GALC-021/2008 y GA-LC-030/2011 y a la ayuda de investigación del Geoparque del Sobrarbe (2011). También agradecemos la financiación conseguida a través de los proyectos HIDROPAST (MEC CGL2010 1637), CGL2009-10455/BTEGRACCIE-Consolider (CSD2007-00067) y Grupo Paleoambientes del Cuaternario. No hubiera sido posible sin la ayuda y colaboración del Servicio Territorial de Mediambiente de Soria, Rubén Gallego (Gestor, Soriaventura), Lorenzo Saéz y Roberto F. García (G.E. Niphargus y Espeleofoto.com), Sergio Blanco (Gestor, Beloaventura), Ramón Queraltó y Carles Pons (Asociación Científico-Espeleológica de Cotiella), y Jaume Mas y Xavier Fuertes (Grupo de Espeleología de Badalona). Agradecemos a Ramiro Moreno y a Miguel Ángel de la Mata por los datos climáticos, a Miguel Sevilla por la figura de localización, a Aida Adsuar y Beatriz Bueno por su apoyo en el trabajo de campo y a Xianfeng Wang y Sushmita Dasgupta por su ayuda con el procedimiento analítico de las dataciones de U-Th.

\section{Referencias bibliográficas}

Bartolomé, M., Moreno, A., Sancho, C., Hellstrom, J., Belmonte, A. 2012. Cambios climáticos cortos en el Pirineo central durante el final del Pleistoceno superior y Holoceno a partir del registro estalagmítico de la cueva de Seso (Huesca). Geogaceta 51, 59-62.

Bartolomé, M., Sancho, C., Moreno, A., Belmonte, A., Bastida, J., Calle, M., Mas, J., Fuertes, X. 2013. Espeleogénesis de la Cueva de Seso (Pirineo central, Huesca). Geogaceta 53, 105-108.

Benito, G., Sancho, C., Peña, J.L., Machado, M.J., Rhodes, E.J. 2010. Large-scale karst subsidence and accelerated fluvial aggradation during MIS6 in NE Spain: climatic and paleohydrological implications. Quaternary Science Reviews 29, 2694-2704.

Berger, A. 1978. Long-term variations of caloric insolation resulting from the Earth's orbital elements. Quaternary Research 9, 139-167.

Bordonaba, A.P., Aurel, M. 2001. El Pliensbachiense de la Rama Aragonesa de la Cordillera Ibérica: análisis secuencial. Geotemas 3 (1), 89-92.

Cuadrat, J.M. 2008. Atlas climático de Aragón. Departamento de Medio Ambiente. Gobierno de Aragón, Zaragoza, 222 pp.

Cheng, H., Edwards, L.R., Hoff, J., Gallup, C.D., Richards, D.A., Asmerom, Y. 2000. The half-lives of uranium-234 and thorium-230. Chemical Geology 169, 17-33.

Domínguez-Villar, D., Vázquez-Navarro, J.A., Cheng, H., Edwards, R.L. 2011. Fresh water tufa record from Spain supports evidence for the past interglacial being wetter than the Holocene in the Mediterranean region. Global and Planetary Change 77, 129-141.

Dorale, J.A., Edwards, R.L., Alexander, E.C., Shen, C.C., Richards, D.A., Cheng, H. 2004. Studies of Cave Sediments: Physical and Chemical Records of Paleoclimate. En Studies of Cave Sediments: Physical and Chemical Records of Paleoclimate, J.E. Mylroie, I.D. Sasowsky (eds.), Kluwer Academy/Plenum Publishers, NewYork, pp. 177-197.

Ford, D., Williams, P. 2007. Karst hydrogeology and geomorphology. John Wiley \& Sons, Chichester, 576 pp.

Fuller, I.C., Macklin, M.G., Lewin, J., Passmore, D.G., Wintle, A.G. 1998. River response to highfrequency climate oscillations in southern Europe over the past 200 k. y. Geology 26, 275-278. 
García-Ruíz, J.M., Moreno, A., González-Sampériz, P., Valero-Garcés, B., Martí-Bono, C. 2010. La cronología del último ciclo glaciar en las montañas del sur de Europa. Una revisión. Cuaternario y Geomorfología 24, 35-46.

Hellstrom, J. 2003. Rapid and accurate U/Th dating using parallelion-counting multi-collector ICP-MS. Journal of Analytical Atomic Spectrometry 18, 1346-1351.

Hellstrom, J. 2006. U-Th dating of speleothems with high initial 230Th using stratigraphical constraint. Quaternary Geochronology 1, 289-295.

Herold, N., Yin, A.Z., Karami, M.P., Berge, A. 2012. Modelling the climatic diversity of the warm inter glacials. Quaternary Science Reviews 56, 126-141.

Lewis. C.J., McDonald, E.V., Sancho, C., Peña, J.L., Rhodes, E.J. 2009. Climatic implications of correlated Upper Pleistocene glacial and fluvial deposits on the Cinca and Gállego Rivers (NE Spain) based on OSL dating and soil stratigraphy. Global and Planetary Change 67, 141-152.

Martinson, D.G., Pisias, N.G., Hays, I.D., Imbrie, J., Moore, T.C., Shackleton, N.J. 1987. Age dating and the orbital theory of the Ice Ages: development of a high-resolution 0 to 300,000year chronostratigraphy. Quaternary Research 27, 1-29.

Martrat, B., Grimalt, J.O., Shackleton, N., de Abreu. L., Hutterli, M.A., Stocker, T.F. 2007. Four climate cycles of recurring deep and surface water destabilizations on the Iberian Margin. Science 317, 502-507.

Mas, J., Fuertes, X. 2007. Cueva del caserío de Seso (Huesca). CIJA de Teruel 2, 30-32.

Meese, D.A., Gow, A.J., Alley, R.B., Zielinski, G.A., Grootes, P., Ram, M., Taylor, K.C., Mayewski, P.A., Bolzan, J.F. 1997. The Greenland Ice Sheet Project 2 depth-age scale: Methods and results. Journal of Geophysical Research 102, 26411-26423.

Millán, H. 2006. Estructura y cinemática del frente de cabalgamiento surpirenaico en las Sierras Exteriores Aragonesas. Colección de Estudios Altoaragoneses 53, 396 pp.

Moreno, A., Stoll, H.M., Jiménez-Sánchez, M., Cacho, L., Valero-Garcés, B., Ito, E., Edwards, L. R. 2010. A speleothem record of rapid climatic shifts during last glacial period from Northern Iberian Peninsula. Global and Planetary Change 71, 218-231.

Moreno, A., González-Sampériz, P., Morellón, M., Valero-Garcés B.L., Fletcher, W.J. 2012. Northern Iberian abrupt climate change dynamics during the last glacial cycle: A view from lacustrine sediments. Quaternary Science Reviews 36, 139-153.

Ninyerola, M., Pons, X., Roure, J.M. 2005. Atlas Climático Digital de la Península Ibérica. Metodología y aplicaciones en bioclimatología y geobotánica. Universidad Autónoma de Barcelona, Bellaterra.

Peña, J.L., Sancho, C., Lewis, C., McDonald, E., Rhodes, E. 2003. Las morrenas terminales de los valles glaciares del Gállego y Cinca (Pirineo de Huesca). Datos cronológicos. Boletín Glaciológico Aragonés 4, 91-109.

Peña, J.L., Sancho, C., Lewis, C., McDonald, E., Rhodes, E. 2004. Datos cronológicos de las morrenas terminales del glaciar del Gállego y su relación con las terrazas fluvioglaciares (Pirineo de Huesca). En El Medio físico de Aragón. Aspectos generales y temáticos, J.L., Peña, L.A. Longares, M. Sánchez Fabre (eds.), Universidad de Zaragoza e Institución Fernando el Católico, Zaragoza, pp. 71-84.

Shackleton, N.J., Sánchez-Goñi, M.F., Pailler, D., Lancelot, Y. 2003. Marine Isotope Substage 5e and the Eemian Interglacial. Global and Planetary Change 36, 151-155.

Soto, R., Casas, A.M. 2001. Geometría y cinemática de las estructuras norte-sur de la cuenca de Aínsa. Revista de la Sociedad Geológica de España 14 (3-4), 199-2.

Spötl, C., Fairchild, I.I., Tooth, A.F. 2005. Cave aircontrol on drip water geochemistry, Obir Caves (Austria): Implications for speleothem deposition in dynamically ventilated caves. Geochimica et Cosmochimica Acta 69, 2451-2468. 
Stoll, H.M., Moreno, A., Méndez-Vicente, A., González-Lemos, S., Jiménez-Sánchez, M., Domínguez-Cuesta, M.J., Edwards, R.L., Cheng, H., Wang, X. En prensa. Growth rates of speleothems in NW Iberian Peninsula over the last two glacial cycles and relationship with climate. Quaternary Research.

Wang, Y., Cheng, H., Edwards, L.R., Kong, X., Shao, X., Chen, S., Wu, J., Jiang, X., Wang, X, An, Z. 2008. Millennial-and orbital-scale changes in the East Asian monsoon over the past 224,000 years. Nature 451, 1090-1093.

White, W.B. 2004. Studies of Cave Sediments: Physical and Chemical Records of Paleo-climate. En Studies of Cave Sediments: Physical and Chemical Records of Paleoclimate, J.E. Mylroie, I.D. Sasowsky (eds.), Kluwer Academy/Plenum Publishers, NewYork, pp. 135-175. 